\title{
Research on the Development Mechanism of China's Power Grid Enterprise under the Background of Global Energy Interconnection
}

\author{
Wenzhuo WU* \\ North China Electric Power University, No.2, Beinong Road, Huilongguan, \\ Changping District, Beijing, China, 102206 \\ e-mail: am18811357955_1@163.com
}

\begin{abstract}
The energy crisis is a global problem. The global energy Interconnection is one of the ways to solve this crisis. This paper first analyzed the current theoretical research situation, and then described the status quo of the theory, analyzes its impact on the power grid and power grid enterprises, so as to obtain the power grid enterprise development mechanism: improve the technical level and enhance their competitiveness continuously, improve the power grid control ability, use "large data" technology widely, to achieve "Internet + ". Finally, this article summarized the above, and gave the policy suggestion.
\end{abstract}

Keywords-Global energy interconnection, Power grid enterprises, Development mechanism

\section{INTRODUCTION}

The Global Energy Interconnection is a new theory based on the global energy outlook and the current state of global energy development, which builds a global perspective to build solutions to the world's energy sustainability. Building a global energy Interconnection will break through the limit of distribution of resources and the number of resources, and will make us fully use clean energy, so that economic and social development gets rid of the dilemma brought about by the plight of energy [1]. The global Interconnection research of domestic scholars is mainly based on its prospects and technological innovation. The literature [2] analyzes the current energy environment and the problems encountered, and gets the solution of the energy problems, then it sums up the significance of building a global energy Interconnection, and looks forward to the prospects of the global energy Interconnection The [3], according to the definition of the concept and the demand of technological innovation, analyzes the role of "large data" in energy Interconnection and completes the four typical application scenarios of "large data". In [4], the cost and benefit are analyzed based on the perspective of microeconomics, and the related benefits are analyzed. The [5] analyzes its significance from the two aspects: energy resources and energy systems. The [6] analyzes the current energy environment in the macro level, and puts forward three keys in the construction of the global energy interconnection. The [7] discusses three major points in the construction of the global energy Interconnection: enhance the development of renewable energy; increase new energy replacement to the transformation and upgrading of old energy; Countries to promote the construction of the global energy Interconnection. And [8] analyzes technology innovation focus areas of the global Interconnection and its key technologies.

On the basis of domestic scholars' research, this paper focuses on the study of the impact of global energy interconnection on power grid enterprise, and then studies its feasible development mechanism in the future and makes policy suggestions on this mechanism.

\section{SITUATION ANALYSIS}

The global energy Interconnection is a strong smart grid which has ultra-high voltage power grid as the backbone of the grid to transport clean energy. This grid is made up of transnational cross-country grids and it covers countries by various voltage-level of power grids. It will connect "Arctic-Equatorial" and energy bases on all continents and adopts various distributed power's accesses. Solar energy, marine energy and other renewable energy can use this platform to be carried to all types of users. It is a global energy distribution platform which has functions as wide range of services, configuration capabilities, high security and reliability, and green low-carbon. It contains an overall layout, two basic principles, three development stages, four important characteristics, five main functions. Its basic framework is shown in Fig.1: 


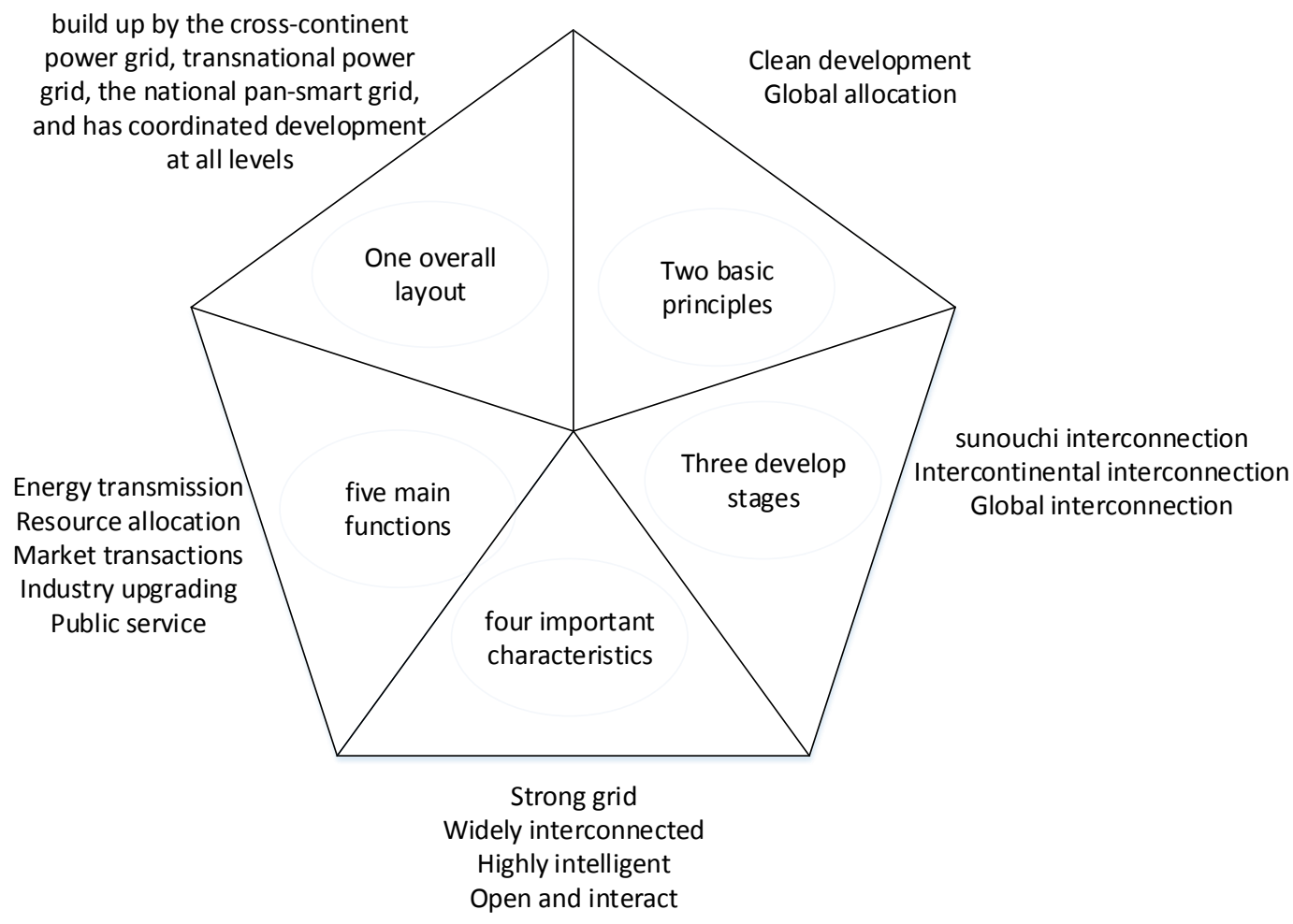

Figure 1. The basic framework of the global energy Interconnection

Its development phases are shown in table1:

Construction of the global energy Interconnection is mainly used to achieve energy "clean" replacement and "green" replacement, the optimal allocation of energy resources, the intensive development of various types of energy and efficient use of energy, the speed of light transmission of energy and electricity. And in company with Roads, waterways, pipelines and other traditional energy transport ways, they can labor in cooperation and complement advantages, so that they can constitute a highly modern global energy transport system together. Its development can form a healthy ecological circle of development, and it will impact the upstream and downstream industries actively. It will have a comprehensive leading role in promoting the overall level of development of the industry and the pace of development, and will be fully integrated into the economic society and intelligent cities' development, becomes an irreplaceable public service hub. Its significance can be summarized as Fig.2:

TABLE I. THE DEVELOPMENT PHASE OF THE GLOBAL ENERGY INTERCONNECTION

\begin{tabular}{c|c|c}
\hline stage & time & goal \\
\hline \multirow{2}{*}{ first } & to 2020 & Promote the formation of consensus. \\
\cline { 2 - 3 } & to 2030 & Start a large clean energy's construction; strengthen the interconnection between \\
countries within the grid.
\end{tabular}




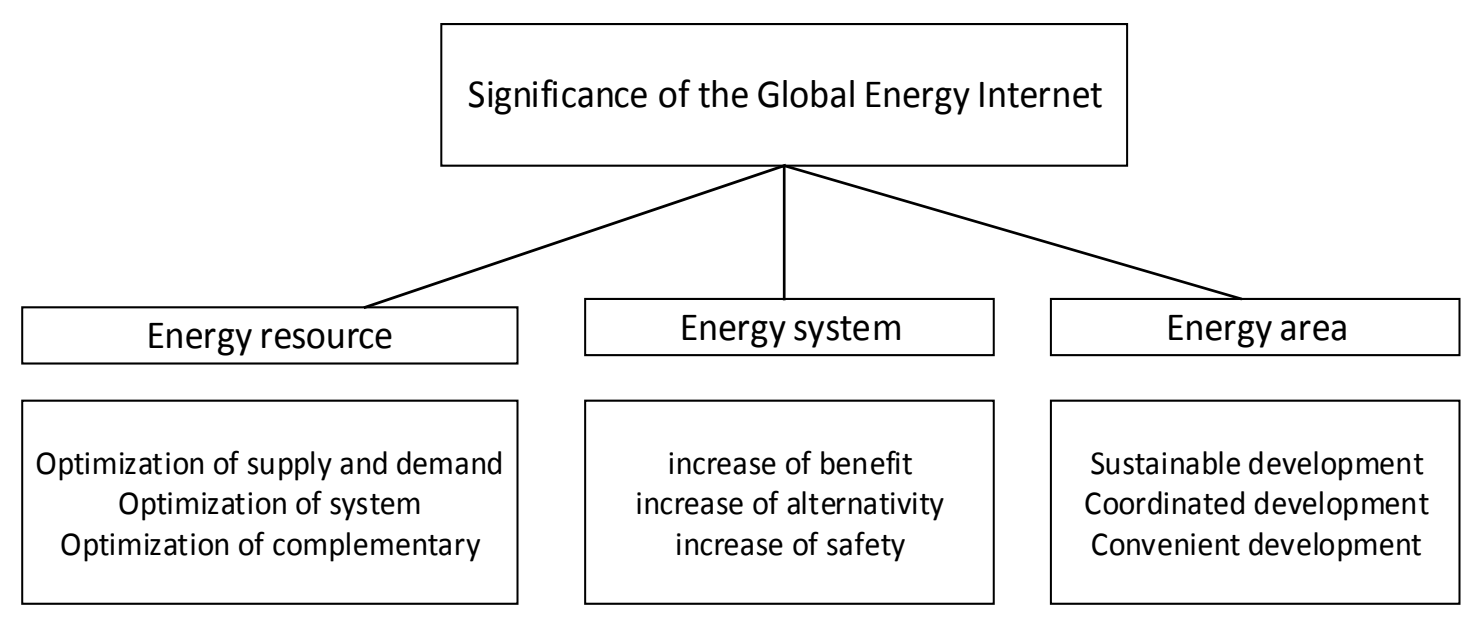

Figure 2. Significance of the Global Energy Interconnection

\section{IMPACT ANALYSIS}

In the context of the global energy Interconnection, "clean" and "electricity" replacement are unstoppable, power grid globalization and intelligence are the trend. Traditional electric power enterprises who are engaged in power purchase and sale business, are responsible for the power grid between the regional power grid transactions and scheduling, are involved in investment and construction and management of cross-regional power transmission and networking projects, are related to power supply's scientific research, technology development, Electricity production scheduling information and communication, consulting services and other businesses, will also face greater opportunities and challenges.

\section{A. It Needs Higher Requirements for Grid Size and Structure}

Based on the definition and characteristics of the global energy Interconnection, the platform is based on the construction of the national pan-smart grid, which is widely connected to the domestic energy bases, all kinds of distributed power and load centers, and can be connected with the surrounding countries' energy. At the same time, the national pan-smart grid can undertake the global energy Interconnection cross-border configuration of clean energy. Therefore, both strong and intelligent are not only the inherent requirements and direction of the smart grid development in the future, but also the essential and center of the development of power grid enterprise in the future.

1) Build a strong grid to improve the transmission capacity of the power grid. In the context of the global energy Interconnection, the grid should be able to ensure flexible access and operation of distributed power, and support large-scale, large-portion of distributed power' access, and support it plug-and-play for distributed power supplies. Therefore, a reasonable grid construction and layout are an important prerequisite for building the global energy Interconnection. In order to achieve national, inter-grid interconnection, and a wide range of global energy configuration, a strong and reliable grid is necessary. Grid is required to be able to effectively resist natural disasters, effective control the impact of emergencies, and be with strong anti-interference and self-healing ability. A reasonable grid layout for the further construction of the Asian interconnected power grid is of great significance.

2) Improve the level of intelligent power grid, and constantly break through the traditional.With the development of intelligent control technology and the mature of grid operate technology, it will have a higher requirement of intelligence of the interconnected power grid in the future, at the same time, it must enhance the intelligent level during power generation, transmission, distribution, electricity, scheduling and communication information, thus our grid can satisfy every kinds of users' need of intelligent electricity.

\section{A HighER DEMAND FOR TECHNOLOGY}

1) Power grid enterprises should focus on large-capacity and long-distance transmission technology. In order to support build intercontinental network and make it possible for remote new energy bases to deliver electricity, it's a trend that transmission technology will develop with greater capacity and higher voltage grade, which has a transmission distance over 3000 kilometers and transmission capacity over 10 million kilowatt, and will have an optimized allocation capability for a large areas' resources. Therefor it is important for power grid enterprises to get breakthrough in UHV DC transmission technology and equipment, flexible DC transmission and DC power grid and other key technologies.

2) Safe operation and control technology of large power grid. The global energy Interconnection is a range of services covering the global power platform, so its grid will also covers the global power users. This fact leads to a higher requirement of Safe operation and control technology of large power grid. In the future, with the development of UHV AC / DC power network and the large scale exploitation of new energy, Safe operation and control of large power grid is facing a huge challenge. On the one hand, UHV AC / DC technology make a profound change of grid operating characteristics. On the other hand, the static characteristics of the new energy generation and the transient characteristics of the grid failure are quite different from those of the conventional 
synchronous generator; it will have a more complex influence on large grid operation. Therefore, the grid companies need to fully grasp the law of the development of large grid, and develop the appropriate grid modeling technology, the whole electromagnetic transient simulation technology, large power grid security control and protection technology, so as to enhance the stability and security of the power grid.

3) The technology of new energy integration. One of the keys to the global energy Interconnection is to achieve "clean" replacement: make clean energy realize its development and utilization, thereby reducing the excessive exploitation of fossil energy. Therefore, in the future power grid companies should also master the technology of new energy integration, so as to be consistent with the construction of this platform. This technology is a key technology to achieve network sources coordination, to ensure the safe and stable operation of the energy Interconnection. In the meantime, in order to meet the inherent needs of the energy Interconnection, power grid companies also need to achieve the forecast of new energy power generation under the complex environment, to achieve large-scale new energy bases' power transmission and regulation.

\section{A. Need for Establishing An Open and Interactive Grid}

The global energy Interconnection will allow users to access this platform. Opening and interaction are its basic requirements. Construction of the global energy Interconnection allows users to interact with a wide range of types of electrical equipment, and builds two-way interaction with the power grid; there energy flows between users and suppliers. Extensive connectivity puts forward new requirements to the grid in the construction of energy Interconnection. Power grid enterprise should continue its "cloud computing, large data, epc system network, mobile internet, smart city" strategy, and combine the Interconnection with the grid, so that intelligent power equipment can approach the users, and power grid enterprise can meet the diversification of services, and thus make business adjustments in a timely manner.

To sum up, the impacts of the global energy interconnection on the power grid enterprises are as shown in Fig.3:

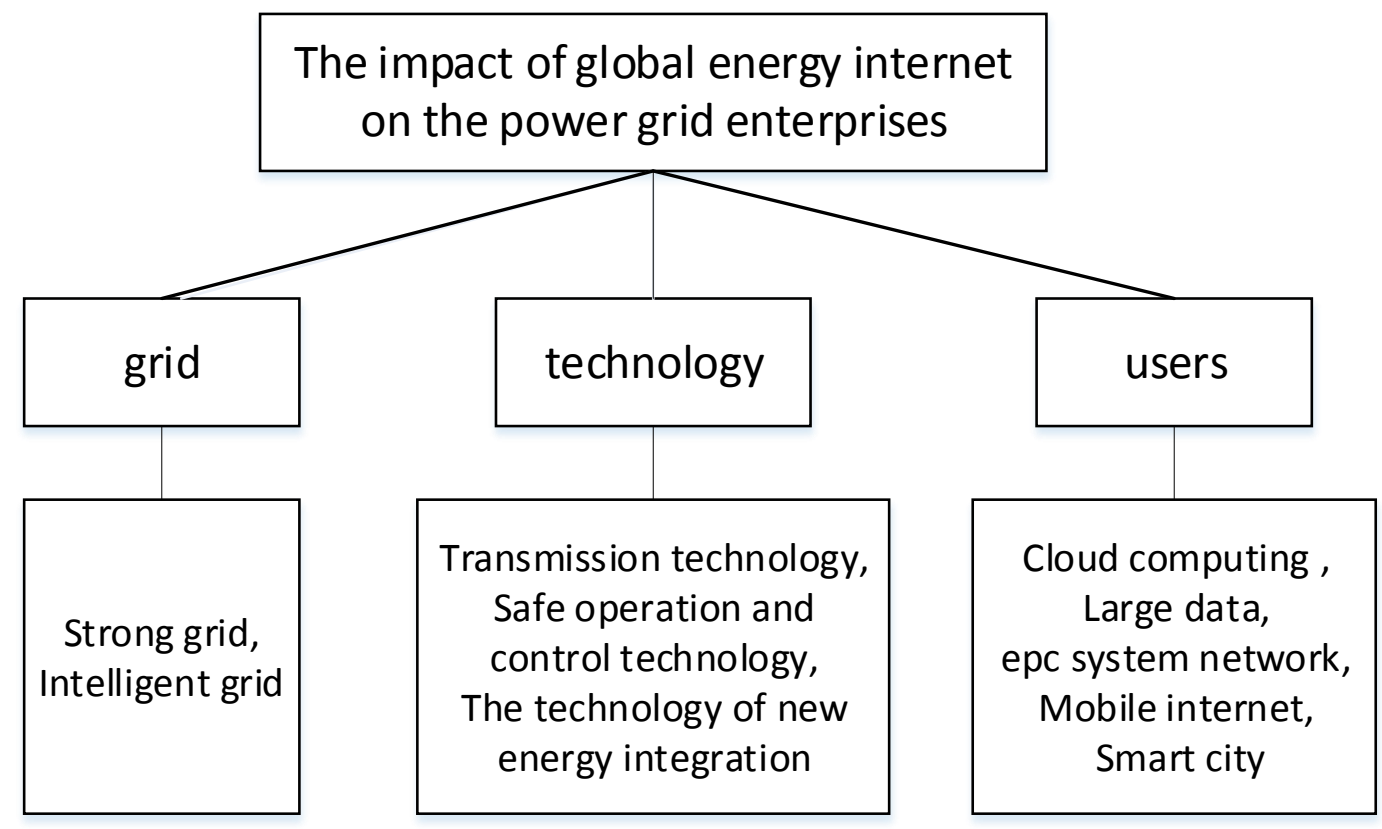

Figure 3. The impact of global energy interconnection on the power grid enterprises

\section{RESEARCH ON DEVELOPMENT MECHANISM OF POWER GRID ENTERPRISE}

From the above analysis we can see that the grid business is a vital part of the global energy Interconnection, it needs to take on its own responsibility and mission. In order to follow the development of the times, in the future grid companies must do the followings:

Improve the technical level and enhance their competitiveness continuously. The essence of the global energy Interconnection is "UHV + smart grid + clean energy", so an important basis for building a global energy Interconnection platform is to build a grid that meets all the requirements. Big capacity transmission, long-distance, low-loss is the inherent requirements of the energy Interconnection. This requires grid companies to continuously improve the UHV technology to meet this demand for power grid construction. In addition, people also want to build up this platform which is safe and intelligent with the ability to self-healing, and this platform can be global interconnected power grid. Therefore, the grid companies need to integrate grid technology and intelligent technology widely, so that the grid realizes its changes from the function of a single power transmission carrier to an intelligent base platform 
which can optimize the configuration of energy resources, and then grid can meet the needs that contain clean energy and distributed power' access, intelligent interaction, intelligent response, system self-healing and others.

Improve the power grid control ability. In the process of building the grid, the grid companies should also be controlled precisely. This requires the grid enterprise continue to overcome the large-scale AC-DC hybrid power grid's safe and stable operation mechanism and characteristic analysis technology, and build a new generation of power grid simulation platform to improve the calculation efficiency and calculation accuracy. In addition, the grid companies also need to break through the power system fault diagnosis, recovery and automatic reconstruction technology, in order to enhance the large power grid defense capabilities under the conditions of chain failure, extreme weather or external damage.

Use "large data" technology widely. The global energy Interconnection is a platform with numerous devices, machines, systems. From the energy production, transmission, trade to energy consumption, each link will produce a lot of data. In addition, due to its high complexity and openness, it will be subject to a variety of internal and external factors. Some intricate relationships are difficult to use accurate physical model to describe and analyze. Thus large data for the platform is indispensable. Power grid enterprise can make a reasonable forecast of energy generation, distribution, conversion and consumption through large data analysis, realize decentralized and centralized energy management, discover the potential risks of each link and ensure the safety and economy of power grid.

To achieve "Internet + ". In the future, if power grid enterprise wants to achieve power grid intelligent, interactive and large power grid safe operation control, it will only have a way that to introduce interconnection in all aspects of their operations. The rapid development of "Internet + intelligent energy" make the grid companies use large data, cloud computing, epc system network, mobile Interconnection and other information technology better, so that the main body of the electricity market can carry out real-time information exchange. Power grid enterprise can achieve the efficiency and security of the entire energy Interconnection through the integration of operational data, meteorological data, grid data, etc. "Internet + " allows the grid to achieve centralized decision-making and hierarchical distribution control, so that the grid can run more stable, and achieve intelligent coordination of defense, equipment on-line detection and fault diagnosis.

In addition to the above content, power grid enterprises should also play their own advantages, take the initiative to expand their business scope and improve service quality in the new electricity market reform. On this basis, power grid enterprises should continue to improve their technical level constantly, with a view to stand in an invincible position during the process of global Interconnection.

\section{CONCLUSIONS AND POLICY RECOMMENDATIONS}

According to the above analysis, if the power grid enterprises want to realize sustainable development in the future, they need to continuously improve their technical level, increase the control of the power grid and master the information technology, so as to achieve the organic integration of the Internet and power grid. In order to construct the global energy interconnection better, China should take the following measures:

Continue to encourage the development of renewable energy. The government should vigorously promote the development of clean energy, implement clean energy priority development strategy, adhere to centralized and distributed energy's co-ordination development, and continue to promote energy structure optimization and green development transformation. Focus should be to speed up the southwest hydropower and the west, the northern new energy intensive development and large-scale delivery, develop various types of distributed clean energy efficiently and orderly.

Encourage innovation to promote energy transformation and upgrading. The government should encourage all types of electricity in the electricity market to focus on innovation of clean energy production, transmission, storage, use and other areas, focus on technical research and development, and make efforts to achieve new breakthroughs in core technology and critical equipment as quickly as possible, so as to promote the industrial restructuring and transformation and upgrading actively.

Make a close contact with the surrounding countries to promote the construction of global energy Interconnection. China should continue to increase cooperation with neighboring countries and energy countries, and increase the proportion of energy imports to Central Asian countries to ensure national energy security. China can also use the strategy "one belt one road" to realize global interconnection in the based on the energy of the domestic Interconnection, and promote international power trade.

\section{REFERENCES}

[1] Zhen-ya LIU. Global Energy Interconnection. [M].Beijing: China Electric Power Press, 2015.01.01. (In Chinese)

[2] Yi-min WANG.2016.Electric Power. (In Chinese)

[3] Dong-xia ZHANG, QIU Robert Cai-ming, Xiao-rong WANG, Chun-yu DENG, Shi-cheng LIU. 2016. Electric Power Information and Communication Technology. (In Chinese)

[4] Ai-jun FAN, Yin-yi PAN. 2016. Fujian Tribune (The Humanities \& Social Sciences Bimonthly). (In Chinese)

[5] An-hua ZHANG.2015.China Power Enterprise Management. (In Chinese)

[6] Li WANG. 2016. Management \& Technology of SME (Late publication). (In Chinese)

[7] Zhen-ya LIU.2015.Electricity \& Culture Today. (In Chinese) 